Check for updates

Cite this: RSC Adv., 2019, 9, 11696

Received 23rd February 2019

Accepted 7th April 2019

DOI: 10.1039/c9ra01386e

rsc.li/rsc-advances

\section{Hydrothermal synthesis and microwave-assisted activation of starch-derived carbons as an effective adsorbent for naphthalene removal}

\begin{abstract}
Pengyun Liu, ${ }^{a}$ Zhansheng Wu, (D) *ab Xinyu Ge ${ }^{c}$ and Xia Yang ${ }^{b}$
In this work, starch-derived spherical carbon $(\mathrm{HC})$ was prepared by hydrothermal carbonization and further activated with microwave assistance to obtain the target activated carbon (HMAC). The samples were characterized by methods of $\mathrm{N}_{2}$ adsorption-desorption, Brunauer-Emmett-Teller analysis, Fourier transform infrared spectroscopy, X-ray photoelectron spectroscopy, elemental analysis and scanning electron microscopy. Moreover, HMAC has a high BET surface area of $616.8 \mathrm{~m}^{2} \mathrm{~g}^{-1}$. The effects of initial naphthalene concentration, contact time, temperature, and $\mathrm{pH}$ of the naphthalene adsorbed on $\mathrm{HC}$ and HMAC were investigated systematically. The HMAC exhibits higher capability for naphthalene removal than $\mathrm{HC}$, and the equilibrium adsorption quantity of HMAC was $223.03 \mathrm{mg} \mathrm{g}^{-1}$ at $303 \mathrm{~K}$. The kinetic data revealed that the equilibrium time for naphthalene adsorption on samples was achieved at $40 \mathrm{~min}$. The adsorption process of $\mathrm{HC}$ and HMAC for naphthalene both followed the pseudo-second-order kinetic and Freundlich isotherm models. Additionally, $\mathrm{H}$-bond and $\pi-\pi$ interactions were proposed to be involved in the adsorption process. An increasing adsorption amount of naphthalene onto HC and HMAC was observed when the $\mathrm{pH}$ value varied from 2 to 10 . The HMAC can be successfully regenerated and maintained sorption performance after three cycles. This study revealed that HMAC obtained by hydrothermal synthesis combined with microwave-assisted activation has a promising application in the field of naphthalene removal.
\end{abstract}

\section{Introduction}

Naphthalene is one of the 16 polycyclic aromatic hydrocarbons (PAHs) included in the Environmental Protection Agency (EPA) list. Hydrocarbons and other organic compounds, such as petroleum, coal, and biomass, are the most extensive sources of naphthalene. ${ }^{1}$ In recent years, naphthalene has attracted more and more attention due to its high toxicity, mutagenicity, and carcinogenicity. $^{2}$ Naphthalene can be transported long distances in water then enriched in soil and living organisms, and is difficult to be effectively degraded by biodegradation because of its chemical stability. ${ }^{3}$

Compared with various physicochemical methods for pollutant removal, adsorption is an effective method for the removal of naphthalene owing to its capability for efficiently adsorbing different kinds of contaminants and simplicity of design. ${ }^{4}$ Researchers have developed a series of adsorbents for the removal of pollutants in liquid phase at present, such as modified

${ }^{a}$ School of Chemistry and Chemical Engineering, The Key Lab. for Green Processing of Chemical Engineering of Xinjiang Bingtuan, Shihezi University, Shihezi 832003, P. R. China. E-mail: wuzhans@126.com; Fax: +86993-2057270; Tel: +86993-2055015

${ }^{b}$ School of Environmental and Chemical Engineering, Xi'an Polytechnic University, Xi'an 710048, P. R. China

${ }^{c}$ Dipartimento di Scienza e Tecnologia del Farmaco, University of Turin, Turin 10125, Italy ligno-cellulosic, ${ }^{5}$ dry waste biofilms, ${ }^{6}$ dried biomass, ${ }^{7}$ calcined oyster shells, ${ }^{8}$ wheat straw ${ }^{9}$ and persea based-activated carbon. ${ }^{10}$

Activated carbons (ACs) possess a high specific surface area, porous character and chemical nature of the surface, so have been widely used as absorbents in recent years. ${ }^{11-13}$ There are many reports on the use of inexpensive, readily available, green, renewable, and carbon-rich valuable by-product materials such as lignocellulosic, ${ }^{14}$ chitosan, ${ }^{15}$ fructose, ${ }^{16}$ and starch $^{17}$ to prepare AC by enabling technologies. Hydrothermal carbonization is considered as an ideal process among several approaches to synthetic carbon materials due to its low-cost, low environmental impact, and the characteristic of contribution to hydrolysis, dehydration, decarboxylation, condensation, polymerization, and aromatization of saccharides in solution. ${ }^{14}$ As far as we know, various materials have been used as precursors for production of hydrochars, such as fructose, ${ }^{16}$ coffee husk, ${ }^{18}$ algal biomass, ${ }^{19}$ cellulose,${ }^{20}$ bamboo sawdust ${ }^{21}$ and pine. ${ }^{22}$ In addition, starch and its derivatives as typical lowcost substances can be used in hydrothermal synthesis of carbon materials and applied to the fields of electrochemistry, engineering and biomedicine..$^{23-25}$

During the carbonization process, subcritical water reacts with starch and transforms into lower molecular weight, such as glucose, which further degrades into furan-based intermediates. ${ }^{18}$ Then, the spherical conjugated aromatic carbonaceous materials were formed via a complex series of reactions 
including polycondensations and Diels-Alder type reactions. ${ }^{16,18}$ Abundant surface functional groups of hydrochars related with precursors and adopted in the hydrothermal carbonization process. However, without the use of any suitable soft- or hard-templates, the obtained carbon materials are nonporous. ${ }^{18,20}$ Therefore, it is necessary to activate hydrothermal carbon via further treatment.

The property of the carbon materials was closely correlated to the activation process. During the activation process, the heating method played a key factor for the physicochemical properties of AC. ${ }^{26}$ As to traditional heating methods, such as inefficient heat transfer methods, time-consuming, and high economic burden has been observed. However, microwave heating is widely used as a promising alternative method because of its distinctive advantages like selective, rapid, uniform, energy-saving, and raising the yield, which converted heat into the particles of materials by dipole rotation and ionic conduction in a short time. Microwaves-assisted activation to prepare AC have been studied. ${ }^{26-28}$ Microwave irradiation can avoid the thermal gradient produced in the traditional heating process. This thermal gradient will hinder the release of pyrolysis gas to the surrounding environment, which makes some volatile components remain in the sample, further leading to the blockage of micropore, and ultimately reducing the performance of activated carbon. Meanwhile, microwave irradiation can also improve the $\mathrm{C} / \mathrm{O}$ ratio of $\mathrm{AC}$ by changing the proportion of oxygen-containing functional groups. ${ }^{29}$ According to C. Cheng et al. and X. Ge et al., microwave irradiation can adjust the pore structure and surface functional groups of AC to obtain high performance adsorbents for removal of adsorbates in aqueous solutions. ${ }^{28,30}$

In the present work, starch is used as a precursor by hydrothermal synthesis to form of carbon material (HC), which was further activated by microwave-assisted irradiation with potassium hydroxide $(\mathrm{KOH})$ to obtain the final activated carbon sample (HMAC). Naphthalene adsorption on HC and HMAC were evaluated $\mathrm{N}_{2}$ adsorption-desorption, Brunauer-EmmettTeller analysis (BET), Fourier transform infrared spectroscopy (FTIR), X-ray photoelectron spectroscopy (XPS), elemental analysis and scanning electron microscopy (SEM) were used to determine the physicochemical properties of starch-derived carbons. The adsorption kinetics, equilibrium adsorption, activation energy, thermodynamics, adsorption mechanisms, $\mathrm{pH}$ influence and regeneration effects of naphthalene on $\mathrm{HC}$ and HMAC in aqueous solution were all studied to identify the adsorption properties and mechanisms.

\section{Materials and methods}

\subsection{Materials}

Starch was purchased from Tianjin Shengao Chemical Reagent Co., Ltd., China. The naphthalene was obtained from Shanghai Tianlong Chemical Co., China. Sulfuric acid and hydrochloric acid were bought from Tianjin Fengchuan Chemical Reagent Technology Co., Ltd. Potassium hydroxide and ethanol were purchased from Tianjin Guangfu Science and Technology Development Co., Ltd. And all chemical reagents and chemicals were of analytical grade.

\subsection{Preparation of $\mathrm{HC}$ and HMAC}

Starch as a precursor was used to obtain a novel carbon material by hydrothermal synthesis. $25 \mathrm{~g}$ starch and $25 \mathrm{~mL}$ of deionized water are mixed in hydrothermal reactor, adjust the reaction solution $\mathrm{pH}$ to 3 with sulfuric acid $\left(1.0 \mathrm{~mol} \mathrm{~L}^{-1}\right)$, and then heated at $473 \mathrm{~K}$ for $24 \mathrm{~h}$ in an oven. It was collected and noted as HC.

The above $\mathrm{HC}$ was further activated by $\mathrm{KOH}$ in a microwave oven (MM823LA6-NS) under vacuum atmosphere. The microwave power and microwave time was set as $700 \mathrm{~W}$ and $15 \mathrm{~min}$, respectively. The further activated samples was collected and washed with $10 \%$ hydrochloric acid and then washed with distilled water until no further $\mathrm{pH}$ change and dried for $4 \mathrm{~h}$ at $383 \mathrm{~K},{ }^{2,3}$ the activated production was noted as HMAC.

\subsection{Characterization methods}

2.3.1 BET surface area and pore size analysis. Surface area and pore size of the HC and HMAC sample were measured using a Micromeritics ASAP 2020 surface area analyzer by nitrogen adsorption-desorption method. The samples were degassed under $\mathrm{N}_{2}$ flow at $308 \mathrm{~K}$ for $6 \mathrm{~h}$ before adsorption isotherms were generated by $\mathrm{N}_{2}$ at $77 \mathrm{~K}$. The surface area $\left(S_{\mathrm{BET}}\right)$ was calculated with the BET equation, and the total pore volume $\left(V_{\mathrm{T}}, \mathrm{m}^{3} \mathrm{~g}^{-1}\right)$ was obtained from the adsorption isotherm at $P / P_{0}$ $=0.95$. Micropore specific surface area $\left(S_{\text {mic }}\right)$ and volume $\left(V_{\text {mic }}\right)$ were obtained using $t$-plot method. ${ }^{6}$ The average pore size $(r)$ was estimated by the eqn (1): ${ }^{3}$

$$
r=\frac{4 V_{\mathrm{T}}}{S_{\mathrm{BET}}}
$$

2.3.2 FTIR analysis. FTIR measurements was performed by mixing a certain amount of samples with $\mathrm{KBr}$ powder and grinded in pellets then adopted a PHI5700 ESCA spectrophotometer to investigate the chemical surface characterization of the HC and HMAC. The FTIR spectra was recorded with a $4 \mathrm{~cm}^{-1}$ resolution and an acquisition rate of 20 scans per min in the infrared domain between 4000 and $400 \mathrm{~cm}^{-1} .^{11}$

2.3.3 XPS analysis. The XPS analysis was conducted using a PHI5700 ESCA system equipped with a $\mathrm{Mg} \mathrm{K} \alpha \mathrm{X}$-ray source $(1253.6 \mathrm{eV})$ under a vacuum pressure $<10^{-6} \mathrm{~Pa}$. Wide scans were conducted from 0 to $1000 \mathrm{eV}$ with a pass energy of $50 \mathrm{eV} .^{3}$

2.3.4 Elemental analysis. Elemental analysis of carbon, hydrogen, nitrogen, and sulfur of HC and HMAC samples were performed using a Vario EL cube analyzer. This process is based on the instantaneous and complete oxidation of the sample at high temperature. The oxygen content was determined by difference method..$^{31,32}$

2.3.5 SEM analysis. SEM (JEOL, JSM-6490LV, Japan) was also employed to study the textural structure of the raw material and its equivalent after the activation process. The morphology of HC and HMAC was characterized by SEM with a secondary electron beam and an acceleration voltage of $8 \mathrm{kV}$. The samples were coated with gold to ensure suitable conductivity of particles after having been dried overnight at $353 \mathrm{~K}$ under vacuum. ${ }^{12}$ 


\subsection{Batch adsorption experiment}

Batch adsorption studies were conducted by mixing $0.015 \mathrm{~g}$ of HC or HMAC with $100 \mathrm{~mL}$ of naphthalene solution of known concentrations, and agitated under $140 \mathrm{rpm}$ until equilibrium were achieved. The effect of adsorption parameters as follows initial naphthalene concentrations $\left(10-50 \mathrm{mg} \mathrm{L}^{-1}\right)$, contact time (0-80 $\mathrm{min})$, temperature $(288-318 \mathrm{~K}), \mathrm{pH}(2-10)$ on the adsorption capacity of $\mathrm{HC}$ and HMAC were investigated. In addition, the regeneration experiment of HMAC was also be performed. Adsorption and regeneration determination were conducted in duplicates.

The adsorption capacity $\left(\mathrm{mg} \mathrm{g}^{-1}\right)$ of naphthalene on $\mathrm{HC}$ and HMAC were calculated according to the following equation: ${ }^{11}$

$$
q_{\mathrm{e}}=\frac{\left(C_{0}-C_{\mathrm{e}}\right) V}{m}
$$

where $C_{0}$ and $C_{\mathrm{e}}\left(\mathrm{mg} \mathrm{L}^{-1}\right)$ are the naphthalene concentrations at initial condition and at a certain time $t(\mathrm{~min})$, respectively, $V(\mathrm{~L})$ is the volume of solution; $m(\mathrm{~g})$ is the mass of $\mathrm{AC}, q_{\mathrm{e}}\left(\mathrm{mg} \mathrm{g}^{-1}\right)$ is the amount adsorbed per unit weight of adsorbents; and $C_{\mathrm{e}}(\mathrm{mg}$ $\mathrm{L}^{-1}$ ) is the equilibrium concentration in the aqueous solution.

\subsection{Adsorption kinetic and isotherm models}

The pseudo-first-order (PFO, eqn (3)), pseudo-second-order (PSO, eqn (4)) and Elovich (eqn (5)) kinetic models were investigated to describe the adsorption equilibrium between adsorbate and adsorbent of the naphthalene-adsorbent system. ${ }^{13}$

$$
\begin{gathered}
\ln \left(q_{\mathrm{e}}-q_{t}\right)=\ln q_{\mathrm{e}}-\frac{K_{1}}{2.303} t \\
\frac{t}{q_{t}}=\frac{1}{K_{2} q_{\mathrm{e}}^{2}}+\frac{t}{q_{\mathrm{e}}} \\
q_{t}=\frac{1}{\beta} \ln (\alpha \beta)+\frac{1}{\beta} \ln (t)
\end{gathered}
$$

where $q_{\mathrm{e}}$ and $q_{t}\left(\mathrm{mg} \mathrm{g}^{-1}\right)$ are the adsorption amounts of naphthalene on to the adsorbents at equilibrium and at time $t(\mathrm{~min})$, respectively. $K_{1}\left(\mathrm{~min}^{-1}\right)$ and $K_{2}\left(\mathrm{~g}\left(\mathrm{mg}^{-1} \min ^{-1}\right)\right)$ are the kinetic rate constants. The $\alpha$ is the initial adsorption rate ( $\mathrm{g}$ $\left(\mathrm{mg}^{-1} \mathrm{~min}^{-1}\right)$ ), and $\beta$ is related to the extent of surface coverage and the activation energy for chemisorption $\left(\mathrm{g} \mathrm{mg}^{-1}\right)$.

The mass transfer mechanism of adsorption was identified by using Weber and Morris model (eqn (6)), and Boyd model (eqn (7)) as follows: ${ }^{10}$

$$
\begin{gathered}
q_{t}=K_{\mathrm{P}} t^{\frac{1}{2}}+C \\
-\ln \left(1-\frac{q_{t}}{q_{\mathrm{e}}}\right)=K_{\mathrm{bf}} t
\end{gathered}
$$

where $K_{\mathrm{p}}\left(\mathrm{mg}\left(\mathrm{g}^{-1} \mathrm{~min}^{-1 / 2}\right)\right)$ and $K_{\mathrm{bf}}\left(\mathrm{min}^{-1}\right)$ are rate constants for intraparticle diffusion and liquid film diffusion, respectively.

The experimental data of the equilibrium research were fitted by Langmuir (eqn (8)), Freundlich (eqn (9)), and Temkin (eqn (10)), and the residual root-mean squared error (RMSE) function values was determined adopting eqn (11), which were written as:

$$
\begin{gathered}
\frac{C_{\mathrm{e}}}{q_{\mathrm{e}}}=\frac{1}{q_{\mathrm{m}}} C_{\mathrm{e}}+\frac{1}{q_{\mathrm{m}} K_{\mathrm{L}}} \\
\ln q_{\mathrm{e}}=\ln K_{\mathrm{F}}+\frac{1}{n} \ln C_{\mathrm{e}} \\
q_{\mathrm{e}}=B \ln A+B \ln C_{\mathrm{e}} \\
\operatorname{RMSE}=\left[\sum_{N=1}^{N}\left(q_{\mathrm{e}, \text { exp }}-q_{\mathrm{e}, \mathrm{cal}}\right) /(N-1)\right]^{1 / 2}
\end{gathered}
$$

where $q_{\mathrm{m}}\left(\mathrm{mg} \mathrm{g}^{-1}\right)$ is the maximum sorption capacity of naphthalene; $q_{\mathrm{e}}\left(\mathrm{mg} \mathrm{g}^{-1}\right)$ is the adsorption amounts of the naphthalene onto the adsorbents at the equilibrium time; $K_{\mathrm{L}}(\mathrm{L}$ $\left.\mathrm{mg}^{-1}\right)$ and $K_{\mathrm{F}}\left(\mathrm{L} \mathrm{mg}^{-1}\right)$ are the Langmuir and Freundlich constants, respectively; $n$ is constant related to the adsorption intensity; $B=R T / b$, with $b\left(\mathrm{~J} \mathrm{~mol}^{-1}\right), A\left(\mathrm{~L} \mathrm{mg}^{-1}\right), R(8.314 \mathrm{~J}$ $\left(\mathrm{mol}^{-1} \mathrm{~K}^{-1}\right)$ ), and $T(\mathrm{~K})$ are the parameters of Temkin isotherm models, which were related to the heat of sorption, equilibrium binding constant, gas constant, and absolute temperature, respectively. And $N$ represents the number of experiments.

\subsection{Adsorption thermodynamics}

The activation energy $\left(E_{\mathrm{a}}, \mathrm{kJ} \mathrm{mol}^{-1}\right)$ of naphthalene adsorption onto adsorbents was obtained from Arrhenius eqn (12): ${ }^{15}$

$$
\ln K_{2}=\ln A-\frac{E_{\mathrm{a}}}{R T}
$$

where $K_{2}$ is the rate constant of pseudo-second-order adsorption, $A$ is the Arrhenius constant, and $R\left(8.314 \mathrm{~J}\left(\mathrm{~K}^{-1} \mathrm{~mol}^{-1}\right)\right)$ is the universal gas constant and $T(\mathrm{~K})$ is the adsorption system temperature.

Furthermore, the thermodynamic parameters of Gibbs freeenergy change $\left(\Delta G, \mathrm{~kJ} \mathrm{~mol}^{-1}\right)$, enthalpy change $\left(\Delta H, \mathrm{~kJ} \mathrm{~mol}^{-1}\right)$ and entropy change $\left(\Delta S, \mathrm{~J}\left(\mathrm{~K}^{-1} \mathrm{~mol}^{-1}\right)\right)$ were calculated to evaluate the thermodynamic feasibility and the spontaneity of the adsorption process. The thermodynamic equations of naphthalene adsorption onto adsorbents were written as follows: ${ }^{11}$

$$
\begin{aligned}
& \Delta G=-R T \ln K_{\mathrm{F}} \\
& \Delta G=\Delta H-T \Delta S \\
& \ln K_{\mathrm{F}}=\frac{\Delta S}{R}-\frac{\Delta H}{R T}
\end{aligned}
$$

where $K_{\mathrm{F}}$ is the adsorption equilibrium constant in eqn (9) for naphthalene and $R\left(8.314 \mathrm{~J}\left(\mathrm{~mol}^{-1} \mathrm{~K}^{-1}\right)\right)$ is the universal gas constant. $\Delta G$ was obtained by employing eqn (13), while $\Delta H$ and $\Delta S$ were calculated from the slope and intercept of the plots of $\ln K_{\mathrm{d}}$ versus $1 / T$, respectively. ${ }^{15}$

\subsection{Effect of initial pH}

The $\mathrm{pH}$ of adsorption system was set as 2, 4, 6, 8, and 10 to investigate the influence of $\mathrm{pH}$ on the adsorption capacity of 

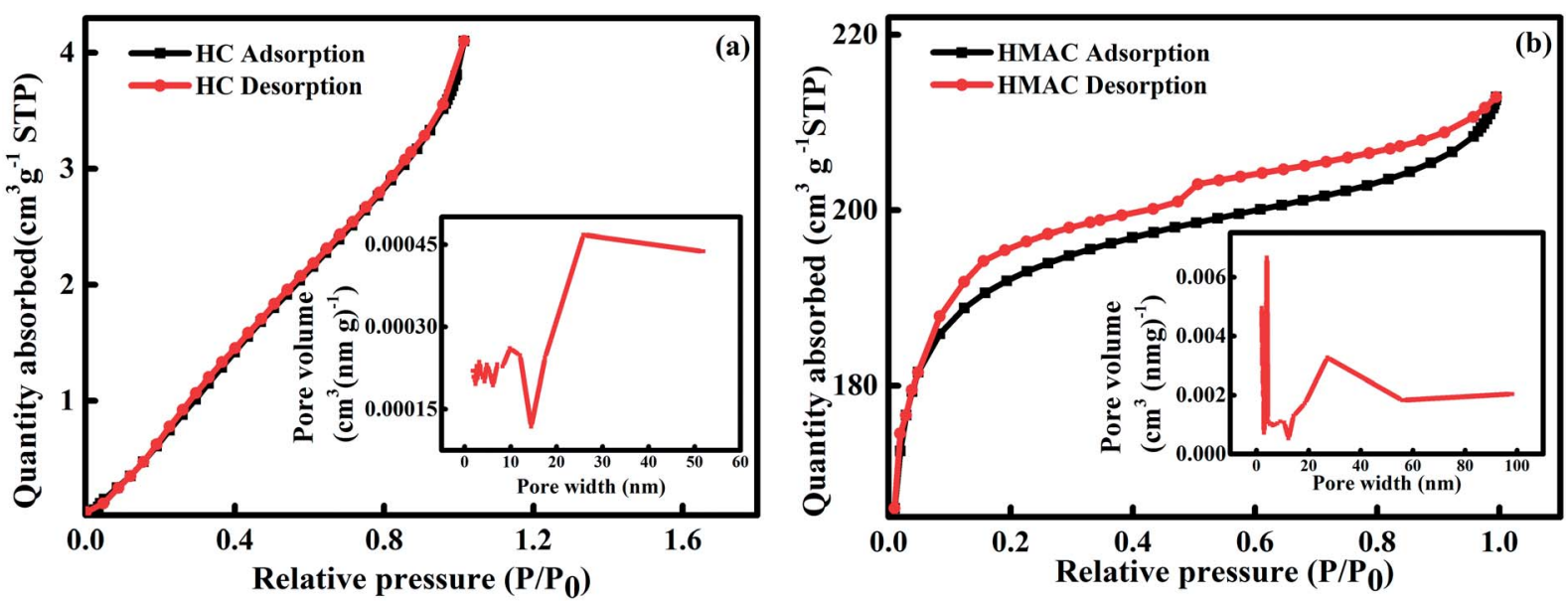

Fig. $1 \mathrm{~N}_{2}$ adsorption-desorption isotherms and pores size distribution of $\mathrm{HC}(\mathrm{a})$ and $\mathrm{HMAC}(\mathrm{b})$.

adsorbents. $0.015 \mathrm{~g}$ adsorbents were added to $100 \mathrm{~mL}$ naphthalene solution with different $\mathrm{pH}$ in $250 \mathrm{~mL}$ sealed-conical flask and then fixed in a constant temperature-shaker under $140 \mathrm{rpm}$ at $303 \mathrm{~K}$.

\subsection{Regeneration of HMAC}

In order to investigate the regenerate of spent HMAC, $0.015 \mathrm{~g}$ of fresh HMAC was mixed with $100 \mathrm{~mL}, 30 \mathrm{mg} \mathrm{L}^{-1}$ naphthalene solution under $140 \mathrm{rpm}$ at $303 \mathrm{~K}$. Furthermore, the spent HMAC was immersed in ethanol $(\geq 98)$ with the assisted of ultrasound for $1.5 \mathrm{~h}$ followed by vacuum drying at $373 \mathrm{~K}$ for $12 \mathrm{~h}$ and then used for regeneration experiment under the same adsorption conditions as fresh samples. ${ }^{12}$

\section{Results and discussion}

\subsection{Characterizations of the HC and HMAC}

3.1.1 $\mathbf{N}_{2}$ adsorption-desorption isotherms. The $\mathrm{N}_{2}$ adsorption-desorption isotherms on $\mathrm{HC}$ and HMAC at $77 \mathrm{~K}$ were measured for BET analysis (Fig. 1). ${ }^{32}$ HMAC isotherm shown a higher porosity than that of $\mathrm{HC}$, which was classified as the type IV with a type- $\mathrm{H}_{4}$ hysteresis loop according to the IUPAC classification. ${ }^{3}$ In addition, the pores size distribution of HC and HMAC were also shown in Fig. 1, both of their pore size were within the mesoporosity range $(2-50 \mathrm{~nm})$ of the IUPAC classification. ${ }^{15}$ The analysis results revealed the BET surface area of HMAC was higher than that of HC (Table 1), indicating that activation with $\mathrm{KOH}$ significantly promotes the specific

Table 1 The BET analysis for $\mathrm{HC}$ and HMAC

\begin{tabular}{llc}
\hline Parameters & HC & HMAC \\
\hline BET specific surface area $\left(\mathrm{m}^{2} \mathrm{~g}^{-1}\right)$ & 8.9 & 616.8 \\
Micropore specific surface area $\left(\mathrm{m}^{2} \mathrm{~g}^{-1}\right)$ & - & 522.65 \\
External specific surface area $\left(\mathrm{m}^{2} \mathrm{~g}^{-1}\right)$ & 8.5295 & 94.1835 \\
Total pore volume $\left(\mathrm{m}^{3} \mathrm{~g}^{-1}\right)$ & 0.0058 & 0.3273 \\
Micropore volume $\left(\mathrm{m}^{3} \mathrm{~g}^{-1}\right)$ & - & 0.2554 \\
Average pore size $(\mathrm{nm})$ & 2.62 & 2.12
\end{tabular}

surface area of $\mathrm{HC}$ and enriches its pore structure. ${ }^{2,3}$ This result was similar with the previous report. ${ }^{25}$ Meanwhile, high micropore specific surface area, external surface specific area, and total pore volume of HMAC, may be beneficial for the adsorption of naphthalene in the solution.

3.1.2 FTIR analysis. FTIR spectrum is used to identify the chemical composition of materials. ${ }^{11}$ Some insignificant changes were observed on the HC and HMAC spectrum (Fig. 2), such as broadening of some bands and spectral shifts. A peak at $3423 \mathrm{~cm}^{-1}$ was observed in the HC and HMAC spectra and can be attributed to the typical stretching vibrations of $\mathrm{O}-\mathrm{H}$ groups, including hydrogen interactions. ${ }^{3}$ The peak at $2920 \mathrm{~cm}^{-1}$ in all the FTIR spectra was characteristic of $\mathrm{C}-\mathrm{H}$ stretching vibrations, suggesting the presence of alkane/alkene groups on the activated carbons surface. ${ }^{13}$ The difference in the intensity of the 1700 and $1590 \mathrm{~cm}^{-1}$ for two samples is attributed to the $\mathrm{C}=\mathrm{O}$ stretching vibration of non-aromatic carboxyl groups with higher intensity in the HC spectrum resulting from the partial dehydrogenation during hydrothermal treatment. ${ }^{3}$ The peak at $1650 \mathrm{~cm}^{-1}$ was ascribed to the $(\mathrm{O}-\mathrm{H})$ bending of tightly bound water present in the starch. ${ }^{10}$ The sharp peaks at $1384 \mathrm{~cm}^{-1}$ in the starch-based carbon materials spectra indicates $\mathrm{S}=\mathrm{O}$ stretching vibrations, due to the presence of sulfate or sulfonyl groups, which were expected since sulfuric acid was used in the synthesis of these materials. ${ }^{13}$ The peaks at approximately $1170 \mathrm{~cm}^{-1}$ represented the $\mathrm{C}-\mathrm{O}$ vibrations of various oxygen-containing groups. The bands around $800-500 \mathrm{~cm}^{-1}$ can be attributed to $\mathrm{C}-\mathrm{H}$ and $\mathrm{CH}=$ $\mathrm{CH}_{2}$ stretching vibrations in aromatic structures. ${ }^{\mathbf{1 2}}$ Based on these results, various functional groups were formed on the surface of HC by hydrothermal treatment. Before and after microwave-assisted chemical activation, the main oxygencontaining groups on the HMAC and HC surface are hydroxyl and carboxyl groups. The slight changes in the peak strength of these two functional groups after activation may be attributed to the formation of volatile gases, such as $\mathrm{CO}$ and $\mathrm{CO}_{2}$ during heating process, ${ }^{27,30}$ which will affect the chemical adsorption of naphthalene by HMAC to a certain extent.

3.1.3 XPS analysis. XPS analysis provides valuable information on the surface chemistry composition of the $\mathrm{HC}$ and 


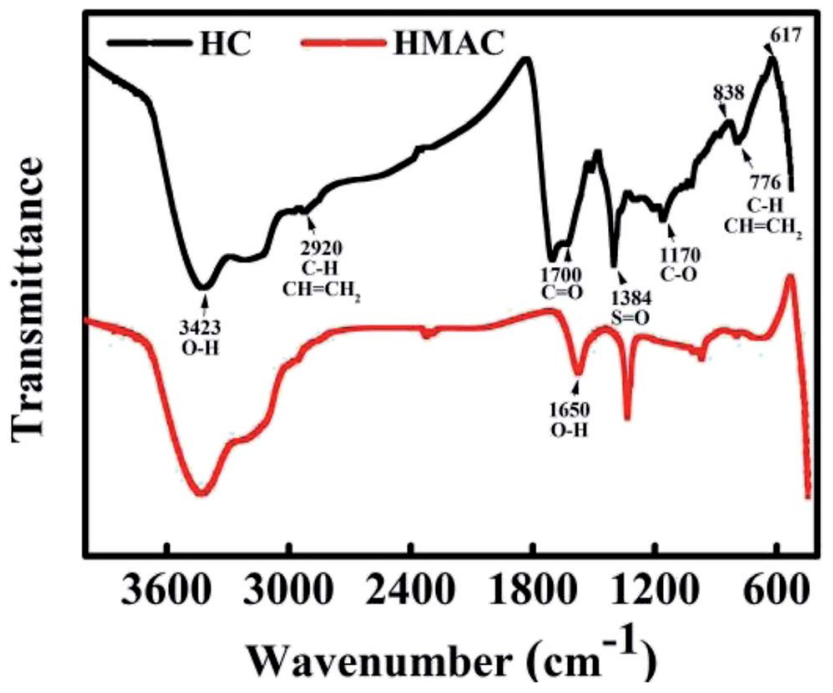

Fig. 2 FTIR spectra of $\mathrm{HC}$ and HMAC.

HMAC by measuring the binding energy of electrons associated with atoms. ${ }^{33}$ The Gaussian-Lorentzian function after baseline subtraction using Shirley's method was adopted for the further analyzing of the $\mathrm{O}$ 1s spectra. Fig. 3a presents the survey XPS spectra of HC and HMAC, and two main peaks were identified and named as $\mathrm{C} 1 \mathrm{~s}$ and $\mathrm{O}$ 1s. It can be seen that the oxygen content decreases and the carbon content increases after activation, which indicates that the proportion of some oxygencontaining functional groups decreases via microwave irradiation. X. Ge et al. have also reported similar results. ${ }^{30}$ For HC and HMAC, which deconvolution of the $\mathrm{O} 1$ s spectra presented four peaks corresponds to $\mathrm{C}=\mathrm{O}, \mathrm{C}-\mathrm{O}, \mathrm{R}-\mathrm{O}^{*}-\mathrm{C}=\mathrm{O}$, and $\mathrm{C}-\mathrm{OOH}$, respectively (Fig. 3b and c). ${ }^{27}$ The parameters of peak position and different $\mathrm{O}$ 1s components for $\mathrm{HC}$ and $\mathrm{HMAC}$ are summarized in Table 2. Compared with HC, there were obviously weaken in the four peaks at $\mathrm{O}$ 1s was observed on HMAC, which suggested that the reduce in the total oxygen-containing functional groups after activation. It was consistent with $\mathrm{C}$ 1s spectra analysis. Moreover, it can be observed that the proportion of $\mathrm{C}=\mathrm{O}$ in HMAC sample significant increases in Table 2, which can enhance the adsorption capacity of naphthalene in aqueous solution by the interaction of $\pi-\pi$ bonds with naphthalene molecules.

3.1.4 Elemental contents analysis. The elemental analysis was designed to obtain the chemical composition and contents of the HC and HMAC, ${ }^{13}$ the analysis results were shown in Table 3. As expected, the $(\mathrm{O}+\mathrm{N}+\mathrm{S}) / \mathrm{C}$ ratios of $\mathrm{HC}$ and HMAC are 0.4802 and 0.4051 , respectively, this result suggested that the polarity order is HC > HMAC, and their the order of hydrophobicity is HMAC $>$ HC. Therefore, HMAC owned more affinity for hydrophobic substrates than $\mathrm{HC}$, which was attributed to the hydrophobicity of the materials decreased when the $\mathrm{O} / \mathrm{C}$
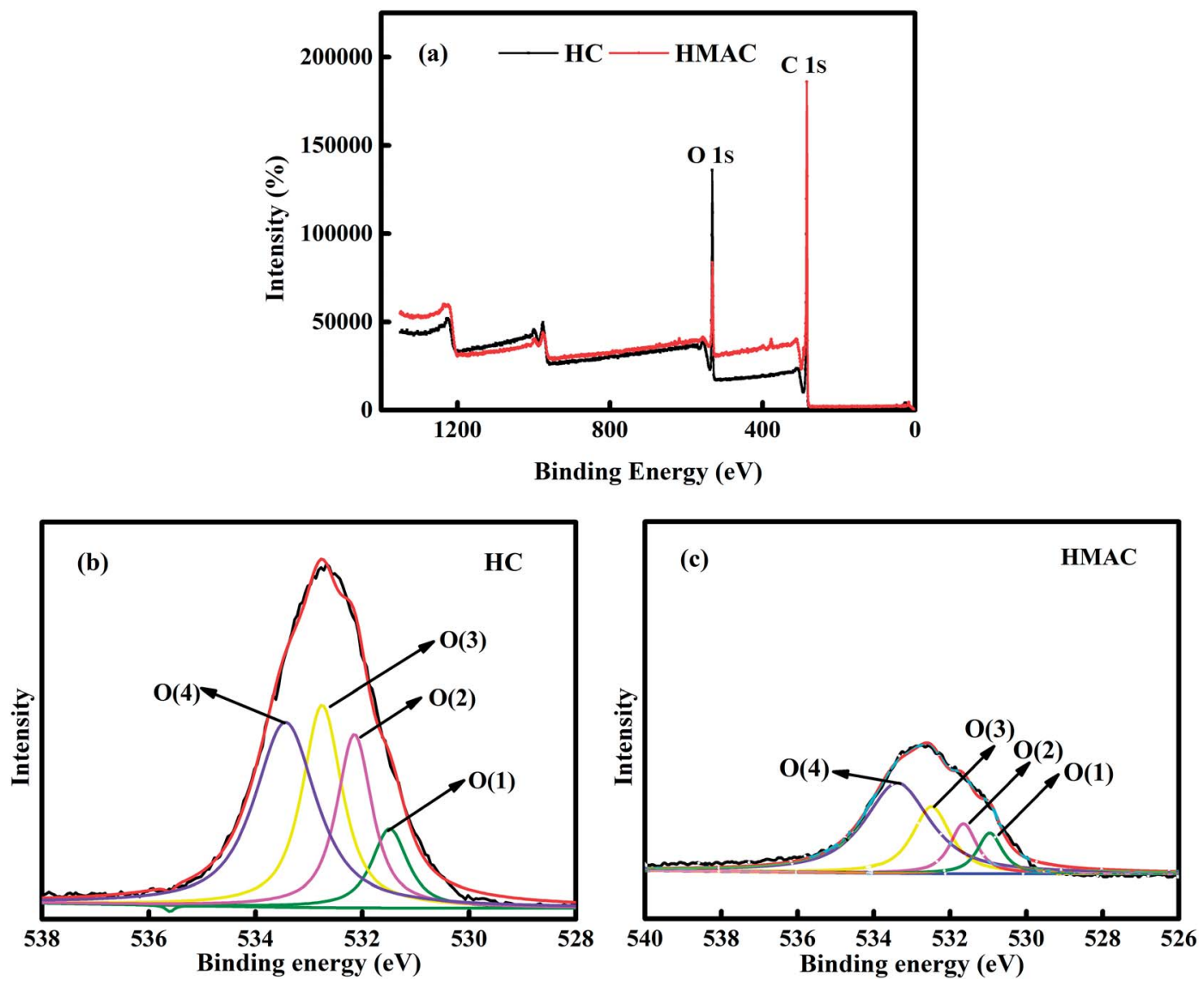

Fig. 3 XPS survey scans (a) and $\mathrm{O}$ 1s profiles of $\mathrm{HC}$ (b) and HMAC (c). 
Table 2 Assignments and peak parameters of different $O$ 1s components of $\mathrm{HC}$ and $\mathrm{HMAC}$

Concentration of each sample (\%)

\begin{tabular}{lllll} 
Component & Assignment & $(\mathrm{eV})$ & HC & HMAC \\
\hline $\mathrm{O}(1)$ & $\mathrm{C}=\mathrm{O}$ & 531.2 & 14.66 & 20.95 \\
$\mathrm{O}(2)$ & $\mathrm{C}-\mathrm{O}$ & 532.4 & 26.68 & 22.69 \\
$\mathrm{O}(3)$ & $\mathrm{R}-\mathrm{O}^{*}-\mathrm{C}=\mathrm{O}$ & 533.3 & 30.42 & 25.96 \\
$\mathrm{O}(4)$ & $\mathrm{O}^{*}=\mathrm{C}-\mathrm{OH}$ & 534.3 & 28.24 & 30.40
\end{tabular}

ratio increases from 0.4002 to 0.4735 . Reduced oxygen content of HMAC indicated the reduction of acidic oxygen functional groups or the introduction of basic groups into the surface of HMAC due to the microwave heating. ${ }^{3}$ These results are consistent with the FTIR analysis.

3.1.5 SEM analysis. The morphology of the HC and HMAC were obtained by SEM images. Fig. 4a depicted dense stacked smooth and complete carbon microspheres, ${ }^{25}$ suggesting that starch was well carbonized and the adsorption mainly occurs on the surfaces of carbon microspheres and their gaps, which also explains the low adsorption quantity of naphthalene on HC. ${ }^{\mathbf{1 0}}$ HMAC has a developed pore structure and most of the carbon microspheres are destroyed (Fig. 4b), which was attributed to the soluble products and gas or organic volatile matter formed during the microwave irradiation-assisted activation process. ${ }^{12}$ The increase of micropore content on HMAC surface will provide more adsorption sites, which will contribute to naphthalene removal, thus leading to its excellent adsorption performance.

\subsection{Adsorption kinetics of naphthalene on HC and HMAC}

The investigation of adsorption kinetics aims to describe the rate of naphthalene adsorption on HC and HMAC and obtain

Table 3 The elemental analysis of $\mathrm{HC}$ and HMAC the equilibrium time. ${ }^{15}$ Fig. 5 shows the sorption kinetics curves of naphthalene on the HC and HMAC, and pseudo-first-order (eqn (3)), pseudo-second-order (eqn (4)), and Elovich (eqn (5)) kinetic models were applied to analyze the adsorption data. The results are listed in Table 4 for further understanding the adsorption kinetic process, the best kinetic model could be identified by the high correlation coefficient $R^{2}$ and low RMSE values. It was observed the adsorption reach to equilibrium after $40 \mathrm{~min}$ for both HC and HMAC. And in comparison, the latter obviously exhibited more excellent adsorption capacity of naphthalene, which may be due to the improvement of pore structure and surface hydrophobicity of HMAC by microwave irradiation-assisted activation. $^{29,30}$ No prominent relationship between pseudo-first-order model and experimental kinetic data was observed towards $R^{2}$. In contrast, the higher $R^{2}$ values of pseudo-second-order kinetic model showed that the kinetics data were well fitted. Similar results have been reported by other researchers. ${ }^{2,3}$ The value of $q_{\mathrm{e}, \exp }$ was in agreement with $q_{\mathrm{e}, \mathrm{cal}}$ while the initial naphthalene concentrations varied from 10 to $50 \mathrm{mg} \mathrm{L}^{-1}$.

\subsection{Equilibrium isotherms of naphthalene adsorption on HC and HMAC}

The adsorption isotherms was used to contact the naphthalene concentration in the adsorption system with the adsorbed amount of naphthalene at the interface and as an unit operation to evaluate the applicability of the adsorption process. ${ }^{12}$ Adsorptions isotherms of $\mathrm{HC}$ and HMAC were obtained by performing naphthalene solution with the concentration of 10$50 \mathrm{mg} \mathrm{L}^{-1}$ (Fig. 6). The experimental data of $\mathrm{HC}$ and HMAC were analyzed by Langmuir, Freundlich, and Temkin isotherm models to obtain information about the nature of adsorption. ${ }^{10,11,15}$ Parameters of these isotherms, such as the maximum adsorption capacity $\left(q_{\max }\right)$, the determination coefficient $\left(R^{2}\right)$,

\begin{tabular}{llllllllll}
\hline Samples & $\mathrm{N} \%$ & $\mathrm{C} \%$ & $\mathrm{H} \%$ & $\mathrm{~S} \%$ & $\mathrm{O}, \operatorname{diff} \%$ & $\mathrm{~N} / \mathrm{C}$ & $\mathrm{H} / \mathrm{C}$ & $\mathrm{O} / \mathrm{C}$ & $(\mathrm{O}+\mathrm{N}+\mathrm{S}) / \mathrm{C}$ \\
\hline HC & 0.02 & 62.98 & 6.78 & 0.40 & 29.82 & 0.0003 & 0.1077 & 0.4735 \\
HMAC & 0.07 & 67.84 & 4.68 & 0.26 & 27.15 & 0.0100 & 0.0690 & 0.4002 & 0.4802 \\
& & & & & & &
\end{tabular}
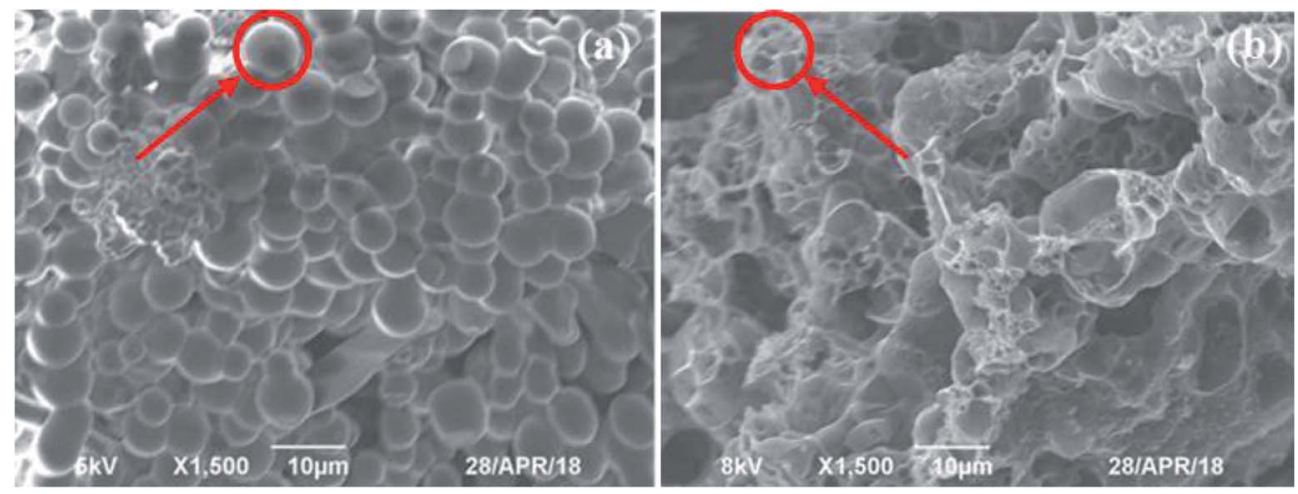

Fig. 4 Scanning electron micrographs of $\mathrm{HC}$ (a) and HMAC (b). 

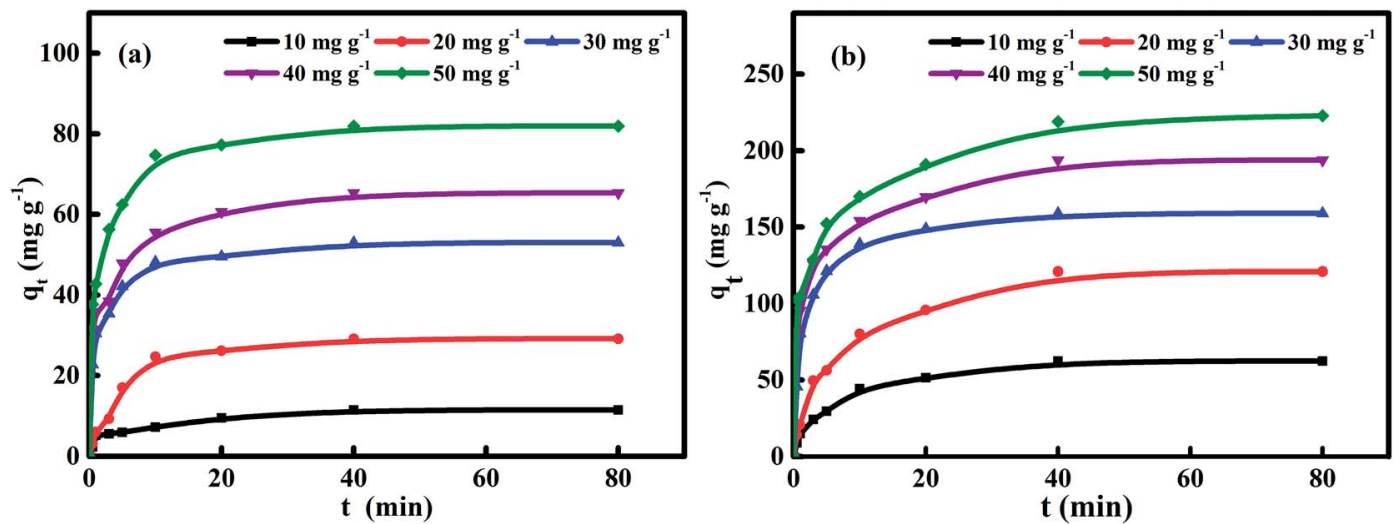

Fig. 5 Naphthalene adsorption kinetics curves of $\mathrm{HC}$ (a) and HMAC (b) at $303 \mathrm{~K}$.

Table 4 Adsorption kinetic parameters of naphthalene onto $\mathrm{HC}$ and HMAC at $303 \mathrm{~K}$

\begin{tabular}{|c|c|c|c|c|c|c|c|c|c|c|c|}
\hline \multicolumn{2}{|l|}{ Models } & $\mathrm{HC}$ & & & & & HMAC & & & & \\
\hline \multicolumn{2}{|c|}{$C_{0}\left(\mathrm{mg} \mathrm{L}^{-1}\right)$} & 10 & 20 & 30 & 40 & 50 & 10 & 20 & 30 & 40 & 50 \\
\hline \multirow[t]{3}{*}{ PFO } & $q_{\mathrm{e}, \mathrm{cal}}\left(\mathrm{mg} \mathrm{g}^{-1}\right)$ & 7.9 & 24.2 & 23.3 & 32.6 & 38.1 & 50.1 & 95.5 & 110.3 & 115.2 & 133.4 \\
\hline & $R^{2}$ & 0.95 & 0.91 & 0.87 & 0.97 & 0.91 & 0.97 & 0.92 & 0.90 & 0.99 & 0.98 \\
\hline & RMSE & 9.5 & 12.3 & 17.1 & 18.9 & 15.4 & 14.5 & 13.8 & 12.0 & 10.0 & 10.8 \\
\hline \multirow[t]{3}{*}{ PSO } & $q_{\mathrm{e}, \mathrm{cal}}\left(\mathrm{mg} \mathrm{g}^{-1}\right)$ & 12.0 & 31.1 & 53.8 & 66.7 & 83.3 & 64.7 & 129.6 & 161.3 & 204.1 & 225.6 \\
\hline & $q_{\mathrm{e}, \mathrm{cal}}\left(\mathrm{mg} \mathrm{g}^{-1}\right)$ & 11.7 & 32.5 & 57.0 & 68.5 & 88.1 & 65.9 & 122.2 & 167.0 & 185.5 & 221.4 \\
\hline & RMSE & 3.1 & 3.3 & 3.9 & 5.2 & 4.5 & 3.5 & 3.2 & 6.7 & 5.5 & 6.8 \\
\hline \multirow[t]{4}{*}{ Elovich } & $(1 / \beta) \ln (\alpha \beta)\left(\mathrm{mg} \mathrm{g}^{-1}\right)$ & 3.85 & 6.74 & 29.88 & 35.56 & 45.80 & 14.70 & 23.14 & 106.16 & 79.04 & 100.14 \\
\hline & $1 / \beta$ & 1.8 & 5.9 & 6.2 & 7.5 & 9.7 & 11.7 & 22.6 & 13.9 & 24.3 & 27.7 \\
\hline & $R^{2}$ & 0.94 & 0.94 & 0.94 & 0.96 & 0.95 & 0.97 & 0.97 & 0.96 & 0.85 & 0.88 \\
\hline & RMSE & 10.9 & 11.3 & 14.6 & 11.0 & 16.7 & 15.5 & 13.1 & 16.2 & 16.0 & 16.1 \\
\hline
\end{tabular}

Langmuir constant $K_{\mathrm{L}}$, Freundlich constant $K_{\mathrm{F}}$, and RMSE values were summarized in Table 5. The Freundlich isotherm model both of HC and HMAC were possessed highest value of $R^{2}$ among the three models, which revealed that the equilibrium experimental data could be better depicted by this model, a similar result was obtained using different ACs. ${ }^{15}$ Additionally, the $1 / n$ of HMAC was in the ranges of $0-1.0$, while the HC has higher value of $1 / n(>1)$ than HMAC, demonstrating that HMAC exhibited excellent adsorption capacity for naphthalene removal compared with HC. All adsorption isotherms were nonlinear (Fig. 6), resulting in the heterogeneous adsorption sites on the HMAC and the different dominant interactions like hydrogen bonding and hydrophobic interactions between adsorbate molecules and adsorbents in the sorption process. ${ }^{13}$ Based on this result, we can conclude that the activation with $\mathrm{KOH}$ was significantly improved the adsorption capacity of HC.
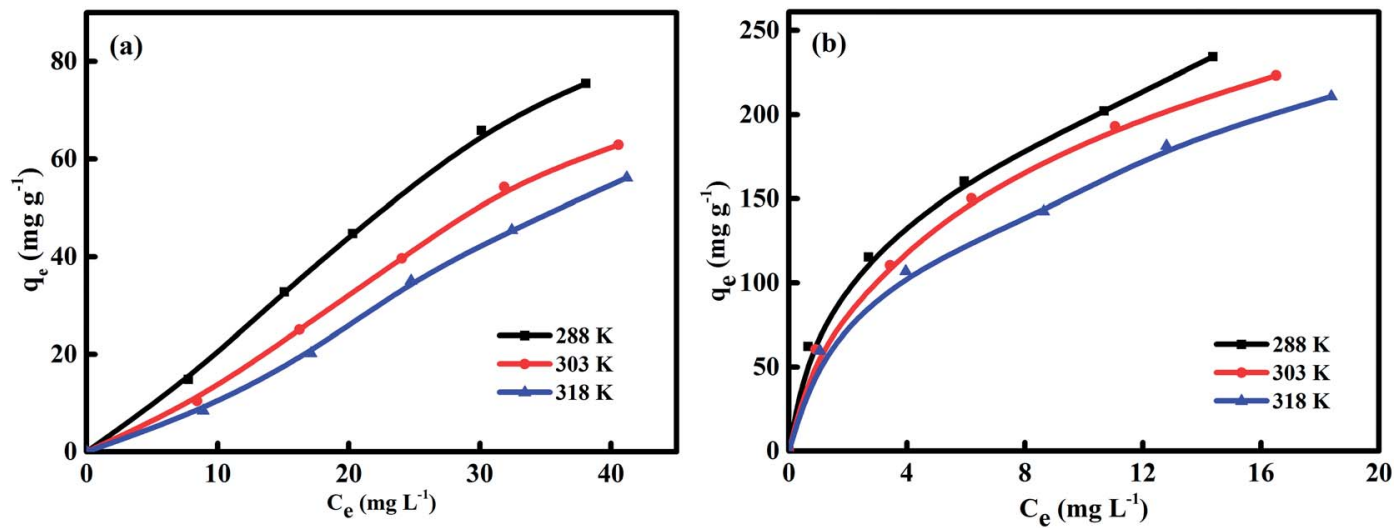

Fig. 6 Equilibrium adsorption isotherms of naphthalene on $\mathrm{HC}(\mathrm{a})$ and $\mathrm{HMAC}$ (b) samples. 
Table 5 Langmuir, Freundlich, Temkin isotherm model constants and correlation coefficients of naphthalene adsorption on HC and HMAC at $303 \mathrm{~K}$

\begin{tabular}{|c|c|c|c|c|c|c|c|}
\hline Models & & $\mathrm{HC}$ & & & HMAC & & \\
\hline Temperature (K) & & 288 & 303 & 318 & 288 & 303 & 318 \\
\hline$q_{\max }\left(\mathrm{mg} \mathrm{g}^{-1}\right)$ & & 16.05 & 7.19 & 3.58 & 277.78 & 256.41 & 238.10 \\
\hline \multirow[t]{3}{*}{ Langmuir isotherm model } & $K_{\mathrm{L}}\left(\mathrm{L} \mathrm{mg}^{-1}\right)$ & 0.032 & 0.034 & 0.033 & 0.295 & 0.342 & 0.525 \\
\hline & $R^{2}$ & 0.77 & 0.80 & 0.73 & 0.97 & 0.99 & 0.96 \\
\hline & RMSE & 9.1 & 11.7 & 9.7 & 9.0 & 9.9 & 9.6 \\
\hline \multirow{4}{*}{$\begin{array}{l}\text { Freundlich isotherm } \\
\text { model }\end{array}$} & $K_{\mathrm{F}}\left(\mathrm{L} \mathrm{mg}^{-1}\right)$ & 1.767 & 1.699 & 1.616 & 75.008 & 64.354 & 58.038 \\
\hline & $1 / n$ & 1.05 & 1.17 & 1.40 & 0.42 & 0.46 & 0.44 \\
\hline & $R^{2}$ & 0.99 & 0.99 & 0.99 & 1.00 & 0.99 & 1.00 \\
\hline & RMSE & 5.5 & 3.4 & 2.8 & 3.8 & 3.7 & 4.5 \\
\hline \multirow{4}{*}{ Temkin isotherm model } & $A\left(\mathrm{~L} \mathrm{mg}^{-1}\right)$ & 0.17 & 0.15 & 0.12 & 4.02 & 4.72 & 6.61 \\
\hline & $B$ & 18.6 & 34.0 & 34.5 & 53.8 & 49.3 & 47.6 \\
\hline & $R^{2}$ & 0.94 & 0.97 & 0.95 & 0.96 & 0.99 & 0.82 \\
\hline & RMSE & 13.5 & 12.9 & 14.2 & 11.9 & 14.0 & 13.2 \\
\hline
\end{tabular}

Thus, starch is a good source for producing preparation an efficient microporous AC with a high capacity for the removal of naphthalene.

\subsection{Adsorption thermodynamics and activation energy}

Table 6 shows the calculated thermodynamic parameters for naphthalene adsorption on HC and HMAC. The negative values of $\Delta G$ declared that adsorption process was spontaneous and thermodynamically unfavorable. ${ }^{12}$ A Van't Hoff plot of $\ln K_{\mathrm{d}}$ versus $1 / T$ provides the $\Delta H$ and $\Delta S$ values. Furthermore, the negative value of $\Delta H$ confirms that the adsorption process is exothermic, agreeing with many reports involving the adsorption of naphthalene on ACs. ${ }^{2,3}$ The positive value of $\Delta S$ suggests an increase in randomness at the adsorbent-liquid interface during naphthalene adsorption, with possible interaction between adsorbate molecules and HC or HMAC. ${ }^{13}$ The randomness or random distribution of sites covered by the adsorbate molecules at the solid-liquid interface were also increased, as indicated by the positive $\Delta S$ values. The activation energy $\left(E_{\mathrm{a}}\right)$ was determined using Arrhenius equation as expressed in the eqn (12). A straight line with a slope of $-E_{\mathrm{a}} / R$ for $\mathrm{HC}$ or HMAC was obtained from $\ln K$ versus $1 / T$ plot for the calculation of $E_{\mathrm{a}} \cdot{ }^{15}$

The values $q_{\mathrm{e}}$ of naphthalene on different adsorbents were compared, HMAC prepared from coal powder by $\mathrm{KOH}$ activation under microwave irradiation in this study is a potential adsorbent for the removal of naphthalene from aqueous solution (Table 7).

\subsection{Adsorption mechanisms}

Whereas Boyd model and Weber-Morris mode ${ }^{13}$ were adopted to further identify the adsorption mechanisms and the rate limiting steps involving the removal of naphthalene with HC and HMAC. It is generally considered that the intraparticle diffusion is a dominant the adsorption process on porous adsorbent. ${ }^{38}$

Fig. 7 suggested the linearly fitted of the experimental data using intraparticle diffusion and film diffusion models. And the parameters of these two models were listed in Table 8. The sorption process of naphthalene on HC and HMAC can be to three steps according Fig. 7a, suggesting that pore diffusion was not only the rate-controlling step and other mechanisms were also involved in the adsorption process..$^{13}$ In the first stage, the fitting straight

Table 6 Thermodynamic parameters for the equilibrium adsorption of naphthalene in aqueous solution onto HC and HMAC

\begin{tabular}{|c|c|c|c|c|c|c|}
\hline \multirow[b]{2}{*}{ Samples } & \multirow[b]{2}{*}{$\Delta H\left(\mathrm{~kJ} \mathrm{~mol}^{-1}\right)$} & \multirow[b]{2}{*}{$\Delta S\left(\mathrm{~J} \mathrm{~mol}^{-1} \mathrm{~K}^{-1}\right)$} & \multirow[b]{2}{*}{$E_{\mathrm{a}}\left(\mathrm{kJ} \mathrm{mol}^{-1}\right)$} & \multicolumn{3}{|c|}{$\Delta G\left(\mathrm{~kJ} \mathrm{~mol}^{-1}\right)$} \\
\hline & & & & $288 \mathrm{~K}$ & $303 \mathrm{~K}$ & $318 \mathrm{~K}$ \\
\hline HMAC & -6.53 & 13.19 & 7.70 & -10.34 & -10.49 & -10.74 \\
\hline
\end{tabular}

Table 7 Comparison of adsorption of naphthalene on various activated carbons

\begin{tabular}{lllrl}
\hline Adsorbents & Initial concentration $\left(\mathrm{mg} \mathrm{L}^{-1}\right)$ & Temperature $(\mathrm{K})$ & Adsorption capacity $\left(\mathrm{mg} \mathrm{g}^{-1}\right)$ & References $^{-1}$ \\
\hline Modified coal-based AC & 30 & 303 & 144.7 & 3 \\
Modified zeolite & 1 & 303 & 0.3 & 3.2 \\
Modified walnut shells & 25 & 298 & 142.7 & 35 \\
ZnS-NPS-AC & 50 & 298 & 17.3 & 36 \\
Modified hazelnut shell & 25 & 298 & 160.7 & 37 \\
HMAC & 30 & 303 & This work
\end{tabular}



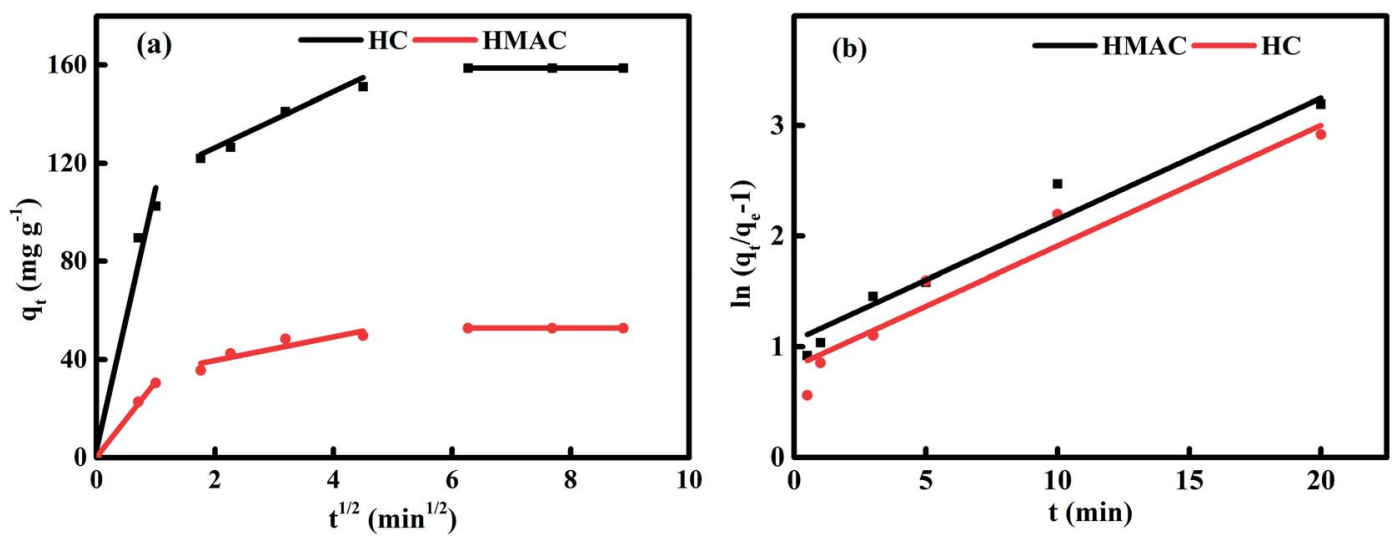

Fig. 7 Plots of intraparticle diffusion (a) and film diffusion model (b) for the adsorption of naphthalene onto HC and HMAC at $303 \mathrm{~K}$.

Table 8 Intraparticle diffusion and film diffusion parameters of naphthalene on $\mathrm{HC}$ and HMAC at $303 \mathrm{~K}$

\begin{tabular}{lllllllll}
\hline & \multicolumn{2}{l}{ Intraparticle diffusion model } & & & \multicolumn{3}{c}{ Film diffusion model } \\
\cline { 2 - 7 } Samples & $K_{\mathrm{p} 1}\left(\mathrm{mg} \mathrm{g}^{-1} \mathrm{~min}^{-1 / 2}\right)$ & $K_{\mathrm{p} 2}\left(\mathrm{mg} \mathrm{g}^{-1} \mathrm{~min}^{-1 / 2}\right)$ & $K_{\mathrm{p} 3}\left(\mathrm{mg} \mathrm{g}^{-1} \mathrm{~min}^{-1 / 2}\right)$ & $\left(R_{1}\right)^{2}$ & $\left(R_{2}\right)^{2}$ & $\left(R_{3}\right)^{2}$ & $K_{\mathrm{bf}}\left(\mathrm{min}^{-1}\right)$ & $R^{2}$ \\
\hline HC & 30.42 & 11.41 & 0.99 & 0.98 & 0.93 & 0.99 & 0.1091 & 0.93 \\
HMAC & 102.52 & 4.82 & 0.99 & 0.99 & 0.91 & 0.99 & 0.1096 & 0.94
\end{tabular}

line was passed through the origin, indicating that there was no boundary layer effect and intraparticle diffusion may be the ratelimited step during the adsorption. Meanwhile, the higher value of $K_{\mathrm{p} 1}$ shown a faster initial sorption rate of naphthalene on HMAC than that of $\mathrm{HC}$, this result proves that HMAC is an efficient adsorbent for naphthalene removal. The low $\left(R_{2}\right)^{2}$ and high intercept value in the second stage suggesting that the intraparticle diffusion was not the only rate-limited step, the external diffusion and the boundary layer diffusion may also effect on the sorption process. And the much smaller value of $K_{\mathrm{p} 2}$ attributed to adsorption equilibrium were reached gradually which was occurred by intra-particle diffusion of naphthalene within HC and HMAC. Therefore, both external mass transfer and intra-particle diffusion were considered existence during the adsorption processes of naphthalene onto HC and HMAC. ${ }^{39}$

Additionally, the adsorption process can be based on the donor-acceptor complex mechanism or $\pi-\pi$ dispersion interactions. The donor-acceptor complex mechanism involves carbonyl oxygen of the carbon surface as donor and the aromatic ring of the naphthalene as an acceptor. The presence of oxygen groups of the HC and HMAC surface enables formation of hydrogen bonds with naphthalene molecules. ${ }^{38}$

\subsection{Effect of pH on adsorption capacity of naphthalene on HC and HMAC}

There were obviously increase for naphthalene adsorption on HC and HMAC when rising the solution pH from 2 to 10 (Fig. 8). At low $\mathrm{pH}$, the electric double layer changes its polarity, which causes a decrease in the adsorbents surface charge density and electrostatic force of attraction, resulting in the low adsorption capacity of HMAC. Meanwhile, the presence of high concentrations of $\mathrm{OH}^{-}$ions at high $\mathrm{pH}$ increasing the negative charge on the HC and HMAC surface where cation attraction and cation exchange processes would take place. ${ }^{\mathbf{4 0 , 4 1}}$ The increase of negative charge on adsorbent surface enhances the electrostatic attraction of naphthalene, thus increasing the adsorption capacity of HMAC and HC to naphthalene. ${ }^{\mathbf{4 2}}$

\subsection{Regeneration of HMAC}

The recyclability regeneration of $\mathrm{AC}$ is important in water or wastewater treatment. There are many reports about the successful regeneration of spent AC by organic solvents.,10,34 The spent HMAC regenerated by using alcohol impregnation was carried out five consecutive adsorption-regeneration cycles for the removal of naphthalene (Fig. 9). The adsorption capacity of naphthalene kept relatively stable adsorption performance

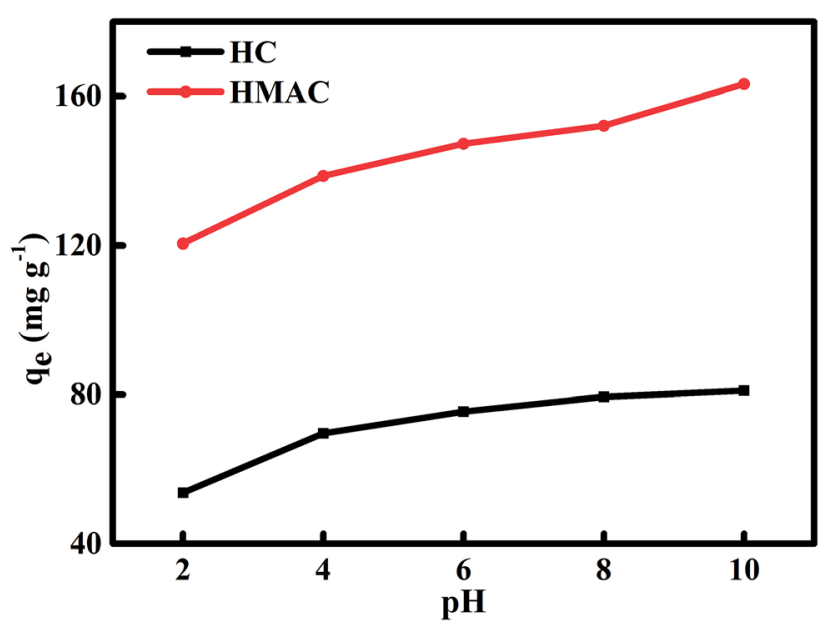

Fig. 8 Influence of solution initial pH on naphthalene adsorption onto $\mathrm{HC}$ and HMAC (naphthalene concentration: $30 \mathrm{mg} \mathrm{L}^{-1}$, contact time: $80 \mathrm{~min}$ ). 


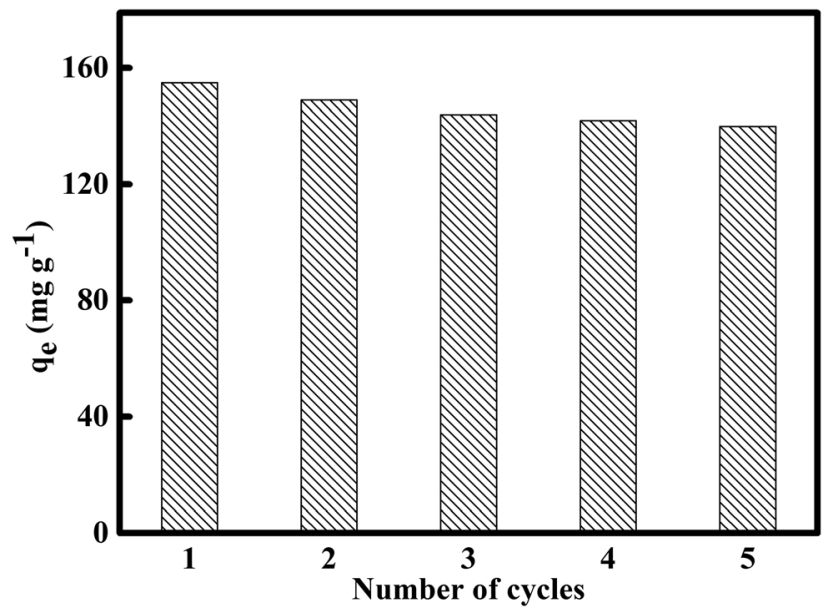

Fig. 9 Reusability of HMAC for the adsorption of naphthalene (naphthalene concentration: $30 \mathrm{mg} \mathrm{L}^{-1}$, contact time: $80 \mathrm{~min}$ ) after solvent washing.

after three adsorption cycle. Therefore, HMAC could be considered to be a relatively cheap, recyclable, and efficient adsorbent for the removal of naphthalene from water. ${ }^{43}$

\section{Conclusions}

Starch as a promising precursor to prepare a novel and low-cost AC for the removal of naphthalene via hydrothermal synthesis and microwave-assisted activation. According to the experimental results, HMAC is possessed well-developed pore structure, high BET surface area, and great microporosity, and both $\mathrm{HC}$ and HMAC exhibited fast rate of adsorption for naphthalene followed the pseudo-second-order rate model. Additionally, HMAC exhibited a better adsorption performance for naphthalene than HC. The investigation of equilibrium adsorption showed that the Freundlich isotherm model had a reasonably fit the experimental data and the maximum naphthalene multilayer adsorption capacity on HMAC was $225.6 \mathrm{mg} \mathrm{g}^{-1}$. The adsorption processes of naphthalene on HMAC and HC were spontaneous and exothermic process. The hydrophobic interactions were likely to dominate mechanism. An increased adsorption amounts of naphthalene on HC and HMAC was observed when $\mathrm{pH}$ varied from 2 to 10 . Moreover, the HMAC could be successfully regenerated and with stable sorption capacity after three cycles. This work indicated that hydrothermal synthesis of starch as well as subsequent chemical activation under microwave-assisted is an alternative to prepare AC with high adsorption capacity of naphthalene.

\section{Conflicts of interest}

There are no conflicts to declare.

\section{Acknowledgements}

This work was supported financially by funding from the National Natural Science Foundation of China (21868034) and the International Science and Technology Cooperation Program of Shihezi University (GJHZ201601).

\section{References}

1 W. Zhang, X. Li, Q. Zhao, Y. Hou, Y. Shen and G. Chen, Mater. Chem. Phys., 2011, 129(3), 683-687.

2 Z. Sun, Z. Wu, D. Liu and X. He, Korean J. Chem. Eng., 2018, 35(2), 557-566.

3 X. Ge, Z. Wu, Z. Wu, Y. Yan, G. Cravotto and B. Ye, J. Taiwan Inst. Chem. Eng., 2016, 64, 235-243.

4 S. Gan, E. V. Lau and H. K. Ng, J. Hazard. Mater., 2009, 172(23), 532-549.

5 Y. Huang, C. Yang, Z. Sun, G. Zeng and H. He, RSC Adv., 2015, 5(15), 11475-11484.

6 H. He, Z. Xiang, X. Chen, H. Chen, H. Huang, M. Wen and C. Yang, Int. J. Environ. Sci. Technol., 2018, 15(7), 1491-1500.

7 Y. Cheng, C. Yang, H. He, G. Zeng, K. Zhao and Z. Yan, J. Environ. Eng., 2016, 142(9), C4015001.

8 X. Inthapanya, S. Wu, Z. Han, G. Zeng, M. Wu and C. Yang, Environ. Sci. Pollut. Res., 2019, 26(6), 5944-5954.

9 M. Wu, H. Liu and C. Yang, Int. J. Environ. Res. Public Health, 2019, 16(2), 1-21.

10 A. Regti, M. R. Laamari, S. E. Stiriba and M. E. Haddad, Microchem. J., 2017, 130, 129-136.

11 M. J. Ahmed, M. d. Azhrul Islam, M. Asif and B. H. Hameed, Bioresour. Technol., 2017, 243, 778-784.

12 K. C. Bedin, A. C. Martins, A. L. Cazetta, O. Pezoti and V. C. Almeida, Chem. Eng. J., 2016, 286, 476-484.

13 S. Alvarez-Torrellas, R. S. Ribeiro, H. T. Gomes, G. Ovejero and J. Garcia, Chem. Eng. J., 2016, 296, 277-288.

14 S. I. Mussatto, M. Fernandes, G. J. M. Rocha, J. J. M. Orfao, J. A. Teixeira and I. C. Roberto, Bioresour. Technol., 2010, 101, 2450-2457.

15 F. Marrakchi, M. J. Ahmed, W. A. Khanday, M. Asif and B. H. Hameed, Int. J. Biol. Macromol., 2017, 98, 233-239.

16 B. Kaludjerovic, V. Mandusic, D. Cokesa, V. Dodevski, S. Krstic, J. Hranisavljevic and S. Milanovic, Zast. Mater., 2017, 58(3), 313-316.

17 S. Zhao, Y. Wang, M. Chen, J. Wang and Z. Shi, J. Phys. Chem. Solids, 2009, 70, 1256-1260.

18 A. Ronix, O. Pezoti, L. S. Souza, I. P. A. F. Souza, K. C. Bedin, P. S. C. Souza, T. L. Silva, S. A. R. Melo, A. L. Cazetta and V. C. Almeida, J. Environ. Chem. Eng., 2017, 5(5), 4841-4849.

19 K. Y. Park, K. Lee and D. Kim, Bioresour. Technol., 2018, 258, 119-124.

20 J. Zhang, Y. An, A. Borrion, W. He, N. Wang, Y. Chen and G. Li, Bioresour. Technol., 2018, 259, 91-98.

21 S. Zhang, Y. Su, D. Xu, S. Zhu, H. Zhang and X. Liu, Bioresour. Technol., 2018, 258, 111-118.

22 Q. Wu, S. Yu, N. Hao, T. Wells Jr, X. Meng, M. Li, Y. Pu, S. Liu and A. J. Ragauskas, Bioresour. Technol., 2017, 244(Pt 1), 7883.

23 B. S. Supriya, P. Nagaraja and K. Byrappa, e-Polymers, 2015, 15(3), 179-183.

24 O. Haibo, L. Cuiyan, H. Jianfeng and F. Jie, RSC Adv., 2014, $4(24), 12586-12589$. 
25 S. Ratchahat, N. Viriyaempikul, K. Faungnawakij and T. Charinpanitkul, Science Journal Ubon Ratchathani University, 2010, 2(1), 40-45.

26 K. Y. Foo, L. K. Lee and B. H. Hameed, Chem. Eng. J., 2013, 223, 604-610.

27 D. Liu, Z. Wu, X. Ge, G. Cravotto, Z. Wu and Y. Yan, J. Taiwan Inst. Chem. Eng., 2015, 59, 563-568.

28 C. Cheng, H. Liu, P. Dai, X. Shen, J. Zhang and T. Zhao, J. Taiwan Inst. Chem. Eng., 2016, 67, 532-537.

29 W. Ao, J. Fu, X. Mao, Q. Kang, C. Ran, Y. Liu, H. Zhang, Z. Gao, J. Li, G. Liu and J. Dai, Renewable Sustainable Energy Rev., 2018, 92, 958-979.

30 X. Ge, Z. Wu, Z. Wu, Y. Yan, G. Cravotto and B. Ye, J. Ind. Eng. Chem., 2016, 39, 27-36.

31 M. I. Konggidinata, B. Chao, Q. Lian, R. Subramaniam and M. Zappi, J. Hazard. Mater., 2017, 336, 249-259.

32 E. Garcia-Bordeje, E. Pires and J. M. Fraile, Carbon, 2017, 123, 421-432.

33 M. Enterría, F. J. Martín-Jimeno, F. Suárez-García, J. I. Paredes, M. F. R. Pereira, J. I. Martins, A. MartínezAlonso, J. M. D. Tascón and J. L. Figueiredo, Carbon, 2016, 105, 474-483.
34 N. Li, W. Cheng and Y. Pan, J. Environ. Prot. Ecol., 2017, 8, 416-425.

35 M. Zhu, J. Yao, L. Dong and J. Sun, Chemosphere, 2016, 144, 1639-1645.

36 M. Ghaedi, A. Daneshyar, A. Asfaram and M. K. Purkait, $R S C$ Adv., 2016, 6, 54322-54330.

37 M. Zhu, W. Tian, H. Chai and J. Yao, Korean J. Chem. Eng., 2017, 34(4), 1073-1080.

38 W. Wang, S. Deng, D. Li, L. Ren, D. Shan, B. Wang, J. Huang, Y. J. Wang and G. Yu, Chem. Eng. J., 2017, 332, 286-292.

39 C. Chen, X. Geng and W. Huang, Chem. Eng. J., 2017, 327, 941-952.

40 X. Duan, C. Srinivasakannan, X. Wang, F. Wang and X. Liu, J. Taiwan Inst. Chem. Eng., 2016, 70, 374-381.

41 X. Wei, Z. Wu, Z. Wu and B. Ye, Powder Technol., 2018, 329, 207-216.

42 C. Du, H. Yang, Z. Wu, X. Ge, G. Cravotto, B. Ye and I. Kaleem, Green Process. Synth., 2016, 5, 1-13.

43 B. N. Bhadra, P. W. Seo and S. H. Jhung, Chem. Eng. J., 2016, 301, 27-34. 